\title{
Sorry-we're full! Access block and accountability failure in the health care system
}

\author{
Grant Innes, MD
}

Emergency department (ED) overcrowding is the number one operational and safety concern in EDs across North America, Australia, and western Europe. $^{1-5}$ Despite diverse attempts to address it, overcrowding is increasing, often reaching crisis proportions in urban hospitals. ${ }^{1,6-10}$ Although "emergency overcrowding" is the usual descriptor, the problem is not overcrowding, and it does not originate in EDs. ${ }^{11} \mathrm{~A}$ more appropriate term is access block, the inability of patients to access care in a reasonable time frame.

Our system suffers widespread access block, with many patients waiting in the wrong place for too long (Table 1). Patients referred for long-term care (LTC) placement wait in acute care hospital beds, compromising access for newly admitted patients. Patients waiting for hospital beds are blocked in ED stretchers, compromising emergency access. In domino fashion, emergency patients are left in hallways or waiting rooms without care. ${ }^{12}$ Emergency care delays lead to prolonged hospital length of stay, ${ }^{13-16}$ inadequate pain management, ${ }^{17,18}$ and increased patient mortality, ${ }^{13,19-27}$ whereas related ambulance offload delays and diversions compromise our prehospital and disaster response systems. ${ }^{3,28-30}$

Capacity shortfalls, efficiency shortfalls, and poor integration between hospital and community are contributing factors, ${ }^{11}$ but the root cause is accountability-a system-level failure to define accountability for patient care and lack of planning to address care gaps. This article discusses the central role of accountability failure in the genesis of widespread access block.

\section{RIGHT CARE, RIGHT PLACE-NOT}

Failure anywhere in the health care system has consequences in EDs. ${ }^{4,31,32}$ When patients need hospital beds but none are available, they wait in ED stretchers. When patients cannot find a family doctor or get a timely appointment, they seek care in the ED. When they call their doctor, they hear recorded messages advising them to go to the ED. When extended care residents deteriorate or become management problems, they are bundled into ambulances and sent to an ED. After surgical procedures, patients are routinely advised to go to the ED if complications arise. When offices and clinics close for the weekend, the Christmas season, or summer vacation, patients converge on EDs. When there are delays in having tests or procedures or accessing specialist care, patients go or are referred to the ED to expedite these. A recent Alberta Health Quality Council survey reported that $58 \%$ of patients attending the ED did so because it was the only place they could access care when they needed it. ${ }^{32}$ More than just a safety net, the ED has instead become the default solution to most system shortfalls. ${ }^{32-38}$

\section{ACCOUNTABILITY ZONES}

A health care system is an organization of people, facilities, and resources that ensures access, quality, and sustainability of health care delivery for its target population. The system's core accountability is patient care, which requires timely patient assessment and disposition; budget, space, and nursing for those requiring program care; contingency plans to address

From the Department of Emergency Medicine, University of Calgary, Calgary, AB.

Correspondence to: Dr. Grant Innes, Department of Emergency Medicine, University of Calgary, 41612 Street NW, Calgary, AB T2N 1Y8; grant. innes@albertahealthservices.ca.

This article has been peer reviewed.

(C) Canadian Association of Emergency Physicians 
Table 1. Examples of emergency, hospital and long-term care access block

Emergency access block: A 35-year-old woman presents to the ED with chest pain. There are 22 inpatients boarding in the ED and all stretchers are full, so she is triaged to the waiting room. Five hours later, still in the waiting room, she collapses, apneic and pulseless. Resuscitation is unsuccessful.

Hospital access block: A 35-year-old psychiatric inpatient with suicidal ideation is waiting in the ED until a ward bed opens up. One locked room is available on the mental health unit, but unit policy mandates that it remain empty in case an inpatient require seclusion. The ED is also full, so the patient is placed in a minor treatment area, where he is visible to ED staff. Shortly after, he escapes through a fire exit and commits suicide.

Long-term care access block: An elderly woman hospitalized for pain management of a pubic fracture develops urosepsis after catheterization. Two weeks later, her sepsis has resolved, but she is deconditioned and no longer capable of independent living. Two weeks later, with no long-term care spaces available, she is still waiting in hospital, physically and cognitively deteriorating.

$E D=$ emergency department

demand variability; and queue management strategies (Table 2). In an effective system, functional units (programs) would be accountable for specific populations. They would develop service delivery plans and rationally allocate people and resources to ensure care for all patients who need it. ${ }^{39}$

The best patient outcomes and system efficiencies occur when patients receive timely care from the right providers in the right place. EDs are designed to provide diagnosis, resuscitation, and management of acute injury or illness over minutes to hours; inpatient surgery programs are designed to manage surgical conditions over days or weeks; mental health programs are designed to deal with psychiatric problems over weeks to months; and rehabilitation programs are designed to optimize long-term functional recovery. Acute care hospital wards do not provide excellent rehabilitative care, and EDs do not provide quality psychiatric care.

In our system, accountability is vague. When patients cannot access the care they need, there is rarely a backup plan, and it is not clear where to look

Table 2. Program accountability for patient care

1. Timely assessment and disposition of patients referred for care

2. Budget, space, and nursing care to look after patients requiring their services

3. Contingency plans to address demand variability

4. Queue management strategies for patients awaiting admission to program care for solutions. Accountability zones $^{40}$ clarify what program is responsible for specific patient needs. The framework in Figure 1 suggests that EDs are accountable for patients who arrive at an ED, hospital-based programs for patients who have been referred for inpatient care, and LTC programs for patients who do not require hospitalization but cannot function independently in the community. Every patient has a home, and every program should have an accountability.

The most accountable program is obvious in the case of a patient requiring fracture fixation, a woman in labor, or a patient requiring mechanical ventilation, but accountability may be unclear at the margins. Logically, care should be provided by the service best able to address a patient's specific needs, but program boundaries differ from one hospital to another based on factors such as practitioner availability and expertise and may even change on a daily basis because of supply and demand fluctuations. Nevertheless, accountability is identifiable in all cases and may be clarified through site-specific policies. When accountability is in dispute (e.g., the septic patient who is "too sick" for a medical unit but "not sick enough" for an intensive care unit), disposition should be resolved by the services at the relevant interface that best understand the factors in play.

Systems characterized by high-input variability and capacity shortfalls require queuing strategiescontingencies for waiting patients. To avoid compromising care elsewhere in the system, these strategies should involve more than blocking access and deferring care to upstream providers. ${ }^{11}$ In an accountable system, EDs, inpatient services, and LTC programs would ensure timely assessment of and disposition for incoming and referred patients, rapid inflow to appropriate care locations, and contingency strategies to ensure access during surges. Program accountability would be defined conceptually, as above, and quantitatively through the use of operational time and flow targets (Table 3).

\section{DISPLACEMENT STRATEGIES: A MANIFESTATION OF ACCOUNTABILITY FAILURE}

To address patient needs in the face of rising demand and limited capacity, programs can lobby for more resources, rationalize the allocation of existing resources, increase efficiency and appropriateness, reduce lengths of stay, and limit the delivery of lowvalue services. But these are difficult options. A simpler 


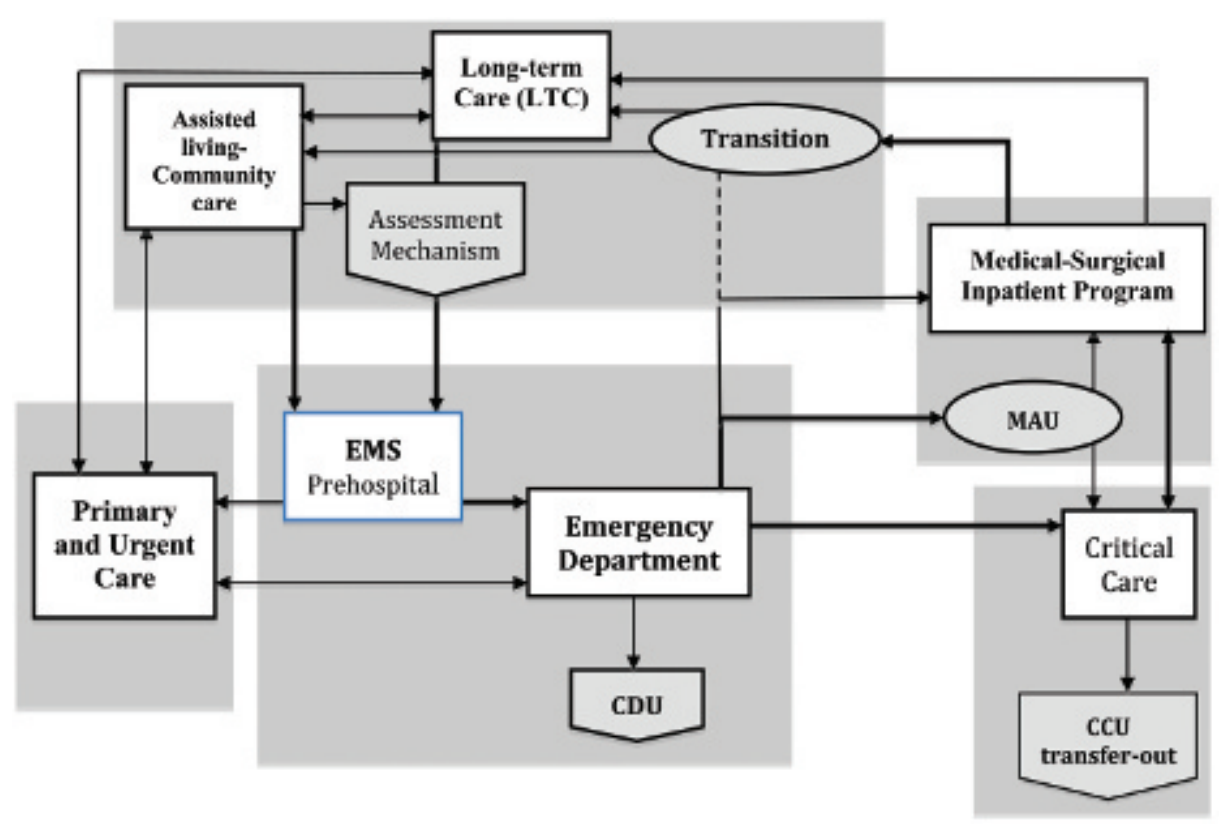

Figure 1. Accountability zones and flow pathways. White boxes denote programs. Grey ovals are inflow areas to key programs. Grey shaded areas reflect accountability zones: the emergency department is accountable for all referrals, walk-in patients, and emergency medical services (EMS) arrivals; inpatient programs are accountable for referred patients; community-LTC programs are accountable for patients designated appropriate for community- or alternate-level care. Grey pentagons denote diversion strategies to limit downstream demand. Fine arrows are current transitions that may be bottlenecks. Thick lines denote free-flow transitions that are activated on a no-refusal, patient-driven ("push") basis. CDU = clinical decision unit; $\mathrm{MAU}=$ medical assessment unit. approach is to block inflow and leave patients in a queue. Therefore, although access block is a problem for patients, it is a default solution and primary coping mechanism for many programs. EDs, inpatient programs, and LTC programs too often address demandcapacity mismatches by closing the door and leaving patients outside.

This practice is triply problematic: it blocks access to patients in need, shifts care to programs that are less capable of providing it, and displaces the consequences of access failure to remote parts of the system. When the consequences of failure in one silo are expressed in a different silo, leaders capable of addressing root causes are protected from having to do so, whereas leaders in impacted areas are incapable of doing so. ${ }^{10,12}$ In an accountable system, consequences would be linked to actions, we would clean up our own backyards, and the program responsible for the wait would provide the waiting room.

\section{Table 3. Sample time and flow targets}

Ambulance offload time in the emergency department: $<30$ min

Time to ED triage: $<10 \mathrm{~min}$

Time to ED physician: 0-120 min, stratified by acuity

Consultation interval (referral to disposition decision): $<2 \mathrm{~h}$

Inpatient transfer delay (admission order to unit transfer): $<2 \mathrm{~h}$

Percentage of hospital beds occupied by alternate level of care

(ALC) patients: $<4 \%$

Time from long-term care referral to transfer (ALC time): $<7$ days

$E D=$ emergency department.
Widespread downloading of care to less effective, more expensive locations compromises appropriateness, utilization, and patient outcomes, but it continues because the rewards for blocking access are profound. Workload is controlled; waiting patients are out of sight and out of mind; staff stress is reduced; budgetary challenges are mitigated; and the program is protected from evolutionary stressors that would otherwise mandate innovation and system change. Without an accountability framework, there is little hope for a high-functioning system.

\section{ACCOUNTABILITY TO THE ONE OR THE MANY?}

A key driver of access block is the lack of clarity around provider accountability. Professionalism in medicine and nursing is typically described using a dyad model that includes a provider and a patient. We feel accountable to the patients we have accepted into our practices and onto our units, but not to the system or patients collectively. We are unaware of the unintended consequences of our actions and do not see the impact on patients not in our direct line of sight. We focus on perfect care for the single patient and offer all treatment options, regardless of cost, and no matter how small the chance of benefit. ${ }^{41}$ In a system with infinite resources, this may be feasible. When beds, tests, and provider time are constrained, such an approach conflicts with the needs of the many. More hospital days, specialist consultations, and computed 
tomographic (CT) scans may confer small benefit to one patient, but at the cost of larger, unrealized benefits and detriment to others., ${ }^{4,42-44}$

The Hippocratic doctrine tells us not to place the interests of the one above the needs of the many ${ }^{40,45}$ but rather to place the needs of individual patients above broader economic and corporate objectives. ${ }^{46}$ Duties to a population take priority over duties to an individual. ${ }^{47}$ We must strive to allocate precious resources rationally and consider the impact of our utilization choices on patients and programs throughout the system. ${ }^{42}$ The Appendix illustrates opportunity cost associated with low-value care.

\section{WASTE AND INEFFECTIVE CARE}

Many believe that ubiquitous queuing is evidence of an underresourced system, in which access blocks cannot be resolved without more facilities, more staff, more testing, and treatment capacity. If this is correct, then we have a problem: we have to work in the real world, where there are limited resources. Ironically, in this context, we currently expend substantial resources on ineffective care, waste, and overuse. Ineffective care, defined as care that does not reduce a patient's subsequent disability, ${ }^{39}$ is pervasive. Hospital days that do not improve outcomes, imaging procedures that do not drive beneficial management changes, physician and nurse activities that do not reduce patient disability, "routine" laboratory testing, expensive drug selection, wasted supplies, avoidable interventions, cardiac monitors for stable patients, and stretchers for people who do not need them are all examples of ineffective care. ${ }^{12,42,48}$ Waste, defined as tests, interventions, or care that does not improve patient outcomes, accounts for up to $30 \%$ of all US health expenditures, whereas overuse (services beyond evidence-based indications) costs about $\$ 300$ billion per annum. This takes care resources from patients who could actually benefit and places patients at risk for iatrogenic harm..$^{34,43,49-51}$ The "choose wisely" campaign has suggested that reducing waste would free up sufficient resources to care for most or all of those needing care. ${ }^{43}$

This premise may be equally valid in Canada, at least as it pertains to hospital access. To illustrate, in 2010, at the zenith of emergency access block at Calgary's Foothills Medical Centre, 50,000 emergent and urgent patients were blocked in waiting areas for an average of 1.6 hours, mostly because of boarded inpatients in the
ED. The emergency access gap totaled 80,000 hours per year and caused many delay-related adverse outcomes. The gap seems huge, but in a 950-bed hospital with 350,000 funded bed days (8.3 million bed hours), an 80,000 -hour emergency care gap equates to $1 \%$ of inpatient capacity. Such a gap could be eliminated by flow adjustments, efficiency improvements, or thoughtful reallocation of care. If we accept that our accountability is to all patients, not merely those already in care, we might reconsider how we deliver services, what services we provide to whom, and how we match care capacity with collective patient need. ${ }^{43}$

\section{IDEAL? APPROPRIATE? OR PERVERSE?}

Doctors and nurses share a common belief that leads to misallocation of care. We believe that what we do is good-therefore, that more is better. More nursing care, more assessments, more hospital days, more monitoring, more tests, and more treatments-all must benefit our patients. In reality, like cardiac preload, more care may be good, but too much is detrimental. There is a sweet spot for health care, a zone of diminishing returns, and a zone where more care leads to harm..$^{51,52}$ Health gain associated with care intensity is not linear. Simple measures provide substantial benefit at low cost, whereas complex and invasive measures generally provide incrementally less benefit at higher cost. ${ }^{51}$ In our attempts to provide ideal care, it is easy to push through the zone of diminishing returns into an area of ineffective or even harmful care (Figure 2). For example, excessive investigation increases the risk of overtreatment and iatrogenic harm, ${ }^{53}$ whereas prolonged hospitalization increases the risk of nosocomial infection, deconditioning, and cognitive and physical deterioration. More care does not always mean better outcomes. ${ }^{42,49,52,54}$

Appropriateness is matching care delivered to care required-providing services that will lead to health gain and not providing services that will not. Our sense of accountability to the one allows us to do the opposite - to provide ideal, excessive, or even ineffective care to one patient while denying essential care to others. By blocking access, we can preserve preferred care practices (sometimes under the guise of "quality") and focus resources on the subset of patients we have accepted. Rather than matching care delivered to care required, this often leads to perverse allocation where acutely ill patients who have not yet been assessed, 


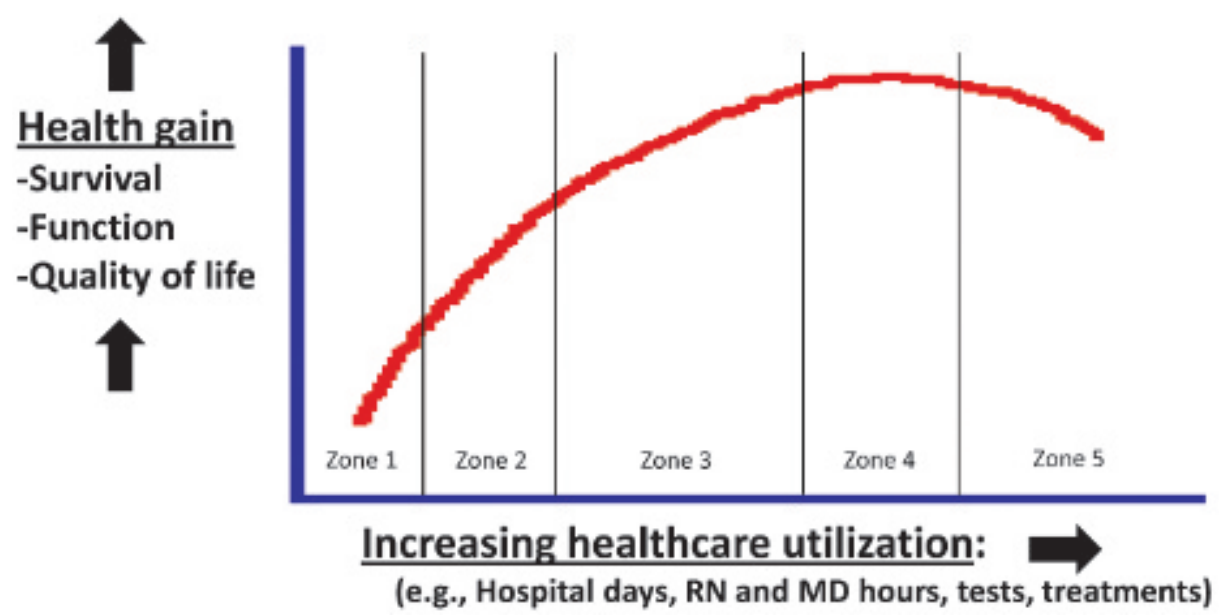

Figure 2. Diminishing return on acute care investment (the Starling curve for utilization). Zone 1: Suboptimal care with unrealized potential health outcome benefit (e.g., failure to provide life- or limb-saving care; inadequate diagnosis and treatment). Zone 2: High benefit care with substantial reduction in mortality or disability (e.g., resuscitation, stabilization, surgical intervention, transfusion, thrombolysis, dysrhythmia control, intravenous antibiotics, trauma management, acute pain control). Zone 3: Lower benefit care, but with some reduction in mortality or disability (e.g., ongoing management, convalescence, teaching, counseling, rehabilitation); may not require an acute inpatient setting. Zone 4: Ineffective care (e.g., unnecessary hospitalization days, redundant information capture by multiple providers, nonbeneficial treatments, repeated assessment or monitoring of stable patients, "routine" tests not acted upon). Zone 5: Harmful care (e.g., prolonged hospitalization with unnecessary immobilization, deconditioning, delirium, exposure to nosocomial infection, poor nutrition and sleep, social isolation, institutionalization). Overdiagnosis (aggressive or invasive detection of insignificant conditions), overtreatment, and iatrogenesis (where the cost or risk of treatment exceeds the likely benefit).

diagnosed, or stabilized are left without care in waiting rooms or ambulance stretchers (see Figure 2). After they are stabilized, diagnosed, and treated, as their need for intervention decreases, they graduate to progressively better circumstances-from a waiting room to an ED stretcher and, ultimately, a private room on an inpatient unit. The most stable patients in the system who require primarily hotel services while awaiting discharge may enjoy the best care circumstances, whereas the sickest wait in hallways outside the front door.

Concordant with the principle that care should be prioritized based on need, "39,43,5,56 Kelen and colleagues described the concept of "reverse triage," whereby as patient need diminishes, priority for hospital resources would also diminish. ${ }^{56}$ Just as patients with the greatest need are triaged in the ED, those with the lowest need for hospital-based intervention would be triaged out the back door. Reverse triage processes are common in EDs, and a multicenter US study showed that this process has the potential to free up a large amount of inpatient capacity. ${ }^{57}$ Unfortunately, process changes that involve rationalizing care are often rejected as "unsafe" because they challenge time-honored or preferred care models and limit our ability to allocate resources as we see fit. ${ }^{10}$ Contingencies that involve less than perfect care go against the grain, but the ethical justification for providing "ideal" care (with low incremental benefit) to some patients while denying essential care to others is questionable., ${ }^{4,39}$ Doyal states that "patient wishes, clinician preferences and standard practices should carry no weight unless there is evidence they will reduce patient disability, and that providing ineffective care is irrational, wasteful and morally indefensible, as it diverts healthcare resources from patients in real need." ${ }_{39,55}$ Effective resource utilization should be considered a core professional responsibility and a valid justification for limiting nonbeneficial interventions, whether these are patient or provider initiated..$^{42}$

\section{PRESCRIPTION FOR CHANGE}

Current operational processes and utilization practices, inappropriate in the context of real resource constraints and widespread access block, are enabled by the lack of an accountability framework and by our narrow view of accountability to individuals over populations. A critical first step in addressing access failure is the development of a framework that clarifies accountability zones and program accountability for patient care. Accountabilities must be established for 
all programs because failures in any one area will have a domino effect, compromising other components of a highly interdependent system.

Care delays will not be solved until someone is accountable to solve them, and people who are unaware of their accountabilities are unlikely to fulfill them. Physicians, nurses, and other care providers must understand who is in their waiting room (accountability zone) and recognize that accepting accountability for the many may require modifying the allocation of health resources. They should critically evaluate their practices and eliminate ineffective care wherever possible.

Accountability is the evolutionary stressor required to drive necessary system change. Its absence is a recipe for failure. Accountability must be defined both conceptually and by time and flow targets. Performance indicators should consider not merely access but also productivity (volume), case mix, efficiency (resource utilization), effectiveness (outcomes), and patient focus (e.g., satisfaction). Performance against targets should be measured and reported. ${ }^{58}$

Accountability must span the system. Ministries of health must drive accountability planning, develop strategic plans, and provide resources for measurement and reporting. They are accountable to provide the clinical infrastructure and resources required for patient care (assuming a high level of efficiency and appropriateness) and for the legislative and labour environment that make it possible or impossible for CEOs, boards, and regional leaders to be effective. ${ }^{59}$

Regional, facility, and program leaders must implement local accountability structures, measurement, and reporting systems. They should monitor care and accountability gaps and then use efficiency and appropriateness measures to determine whether these are best addressed through new capacity, enhanced efficiency, or reallocation of existing resources. Where the core problem is capacity, they must be advocates for expansion. Where the core problem is program inefficiency or misallocation, they must demand change.

Most important, system leaders must remove incentives for failure ${ }^{59}$ because widespread dependence on access block as a coping strategy has reduced the need for operational innovation and doomed many access and flow initiatives. Protection from evolutionary stressors is not the way to drive innovation: As long as it is acceptable to address program shortfalls by blocking access and displacing the problem elsewhere, access block will remain a solution to be exploited rather than a problem to be eliminated.

"Sorry-we're full!" doesn't cut it any more.

Keywords: access, access block, emergency, flow overcrowding Competing interests: None declared.

\section{REFERENCES}

1. Institute of Medicine Committee on the Future of Emergency Care in the United States Health System, Hospital-based emergency care: at the breaking point. Washington (DC): National Academies Press; 2006. Executive summary available at: http://www.nap.edu/catalog/11621.html (accessed August 10, 2012).

2. Canadian Association of Emergency Physicians. Access to acute care in the setting of emergency department overcrowding. CFEM 2003;5:81-6.

3. Fatovich DM, Nagree Y, Sprivulis P. Access block causes emergency department overcrowding and ambulance diversion in Perth, Western Australia. Emerg Med 7 2005;22:3514, doi:10.1136/emj.2004.018002.

4. American College of Emergency Physicians Task Force on Boarding. Emergency department crowding: high-impact solutions. Available at: http://www.acep.org/clinical---practicemanagement/2008-emergency-department-crowding-report-high-impact-solutions (accessed October 25, 2013).

5. Rowe $\mathrm{BH}$, Bond $\mathrm{K}$, Ospina $\mathrm{MB}$, et al. Emergency department overcrowding in Canada: what are the issues and what can be done? Technology overview No 21. Ottawa: Canadian Agency for Drugs and Technologies in Health; 2006.

6. Hoot NR, Aronsky D. Systematic review of emergency department crowding: causes, effects, and solutions. Ann Emerg Med 2008;52:126-36, doi:10.1016/j.annemergmed. 2008.03.014.

7. Kellermann AL. Crisis in the emergency department. N Engl 7 Med 2006;355:1300-3, doi:10.1056/NEJMp068194.

8. Canadian Association of Emergency Physicians. Position statement on overcrowding 2009. Available at: http://caep. $\mathrm{ca} /$ resources/position-statements-and-guidelines (accessed October 25, 2013).

9. Pitts SR, Pines JM, Handrigan MT, Kellermann AL. National trends in emergency department occupancy, 2001 to 2008: effect of inpatient admissions versus emergency department practice intensity. Ann Emerg Med 2012;60:67986, doi:10.1016/j.annemergmed.2012.05.014.

10. Moskop JC, Sklar DP, Geiderman JM, et al. Emergency department crowding-barriers to reform and strategies to overcome them. Ann Emerg Med 2009;53:612-7, doi:10. 1016/j.annemergmed.2008.09.024.

11. Bell R, Willett J, Oliver J. An Expert Working Group reporting to the Physician Hospital Care Committee, a tripartite committee of the Ontario Hospital Association, the Ontario Medical Association and the Ontario Ministry of Health and Long-Term Care. 2006. Improving access to emergency care: addressing system issues. 
12. Canadian Institute for Health Information. Access to inpatient beds and patient flow. Available at: https://secure.cihi.ca/ estore/productSeries.htm? locale $=$ en\&pc $=$ PCC289 (accessed October 26, 2013).

13. Chalfin DB, Trzeciak S, Likourezos A, et al. Impact of delayed transfer of critically ill patients from the emergency department to the intensive care unit. Crit Care Med 2007;35: 1477-83, doi:10.1097/01.CCM.0000266585.74905.5A.

14. Liew D, Liew D, Kennedy MP. Emergency department length of stay independently predicts excess inpatient length of stay. Med F Aust 2003;179:524-6.

15. Richardson DB. The access-block effect: relationship between delay to reaching an inpatient bed and inpatient length of stay. Med 7 Aust 2002;177:492-5.

16. Krochmal P, Riley TA. Increased health care costs associated with ED overcrowding. Am 7 Emerg Med 1994;12:265-6, doi:10.1016/0735-6757(94)90135-X.

17. Hwang P, Richardson LD, Sonuyi TO, et al. The effect of emergency department crowding on the management of pain in older adults with hip fracture. 7 Am Geriatr Soc 2006; 54:270-5, doi:10.1111/j.1532-5415.2005.00587.x.

18. Pines JM, Hollander JE. Emergency department crowding is associated with poor care for patients with severe pain. Ann Emerg Med 2008;51:1-5, doi:10.1016/j.annemergmed.2007. 07.008 .

19. Geelhoed GC, de Klerk NH. Emergency department overcrowding, mortality and the 4-hour rule in Western Australia. Med 7 Aust 2012;196:122-6, doi:10.5694/mja 11.11159 .

20. Sprivulis PC, DaSilva JA, Jacobs IG, et al. The association between overcrowding and mortality among patients admitted via Western Australian emergency departments. Med 7 Aust 2006;184:208-12.

21. Richardson DB. Increase in patient mortality at 10 days associated with emergency department overcrowding. Med 7 Aust 2006;184:213-6.

22. Guttmann A, Schull MJ, Vermeulen MJ, Stukel TA. Association between waiting times and short-term mortality and hospital admission after departure from emergency department: population based cohort study from Ontario, Canada. BMf 2011;342:d2983, doi:10.1136/bmj.d2983.

23. McCarthy ML, Zeger SL, Ding R, et al. Crowding delays treatment and lengthens emergency department length of stay, even among high-acuity patients. Ann Emerg Med 2009; 54:492-503, doi:10.1016/j.annemergmed.2009.03.006.

24. Schull MJ, Vermeulen M, Slaughter G, et al. Emergency department crowding and thrombolysis delays in acute myocardial infarction. Ann Emerg Med 2004;44:577-85, doi:10.1016/j.annemergmed.2004.05.004.

25. Scheuermeyer FX, Christenson J, Innes G, et al. Safety of assessment of patients with potential ischemic chest pain in an emergency department waiting room: a prospective comparative cohort study. Ann Emerg Med 2010;56:455-62, doi:10.1016/j.annemergmed.2010.03.043.

26. Kulstad B, Kelley KM. Overcrowding is associated with delays in percutaneous coronary intervention for acute myocardial infarction. Int 7 Emerg Med 2009;2:149-54, doi:10.1007/s12245-009-0107-x.

27. Fee C, Weber EJ, Maak CA, et al. Effect of emergency department crowding on time to antibiotics in patients admitted with community-acquired pneumonia. Ann Emerg Med 2007;50:501-9, doi:10.1016/j.annemergmed.2007.08. $\underline{003}$.

28. Eckstein M, Chan LS. The effect of emergency department crowding on paramedic ambulance availability. Ann Emerg Med 2004;43:100-5, doi:10.1016/S0196-0644(03)00747-9.

29. Fatovich DM, Hirsch RL. Entry overload, emergency department overcrowding, and ambulance bypass. Emerg Med 7 2003;20:406-9, doi:10.1136/emj.20.5.406.

30. Barbera JA, Macintyre AG, DeAtley CA. Ambulances to nowhere: America's critical shortfall in medical preparedness for catastrophic terrorism. BCSIA Discussion Paper 2001-15, ESDP Discussion Paper ESDP-2001-07. Boston: John F. Kennedy School of Government, Harvard University; October 2001.

31. Institute of Medicine, Future of Emergency Care. Hospitalbased emergency care: at the breaking point. Washington (DC): The National Academies Press; 2006.

32. Health Quality Council of Alberta. Review of the quality of care and safety of patients requiring access to emergency department care and cancer surgery. 2012.

33. Government Accountability Office. GAO report: crowding continues to occur, and patients wait longer than recommended time frames. April 2009. Available at: http://www.gao.gov/ assets/290/289054.html (accessed October 25, 2013).

34. Yong PL, Saunders RS, Olsen LA, editors, Institute of Medicine, The bealthcare imperative: lowering costs and improving outcomes: workshop series summary. Washington (DC): The National Academies Press; 2010.

35. Schuur JD, Venkatesh AK. The growing role of emergency departments in hospital admissions. N Engl 7 Med 2012;367: 391-3, doi:10.1056/NEJMp1204431.

36. Morganti KG, Bauhoff S, Blanchard JC. The evolving role of emergency departments in the United States. Santa Monica (CA): RAND Corporation; 2013.

37. Tang N, Stein J, Hsia RY, et al. Trends and characteristics of US emergency department visits, 1997-2007. FAMA 2010;304:664-70, doi:10.1001/jama.2010.1112.

38. Gindi RM, Cohen RA, Kirzinger WK. Emergency room use among adults aged 18-64: early release of estimates from the National Health Interview Survey, fanuary-June 2011. National Center for Health Statistics; May 2012. Available at: http://www.cdc.gov/nchs/nhis/releases.htm.

39. Doyal L. Needs, rights and equity: moral quality in healthcare rationing. Qual Healthc 1995;4:273-83, doi:10. 1136/qshc.4.4.273.

40. Emanuel EJ, Emanuel LL. What is accountability in health care? Ann Intern Med 1996;124:229-39, doi:10.7326/00034819-124-2-199601150-00007.

41. Robertson J, Walkom EJ, Henry DA. Health systems and sustainability: doctors and consumers differ on threats and solutions. PloS One 2011;6(4):e19222, doi:10.1371/journal.pone.0019222.

42. Brett AS, McCullough LB. Addressing requests by patients for nonbeneficial interventions. FAMA 2012;307:149-51, doi:10.1001/jama.2011.1999.

43. Brody H. From ethics of rationing to ethics of waste avoidance. $N$ Engl 7 Med 2012;366:1949-51, doi:10.1056/ NEJMp1203365. 
44. Smith R, Hiatt H, Berwick D. Shared ethical principles for everybody in health care: a working draft from the Tavistock group. BM7 1999;318:248-51, doi:10.1136/bmj.318.7178.248.

45. Shortell SM, Waters TM, Clarke KWB, et al. Physicians as double agents: maintaining trust in an era of multiple accountabilities. FAMA 1998;280:1102-8, doi:10.1001/jama. 280.12.1102.

46. Davies HTO, Nutley SM, Mannion R. Organizational culture and quality of health care. Qual Health Care 2000;9: 111-9, doi:10.1136/qhc.9.2.111.

47. Girod J, Beckman AW. Just allocation and team loyalty: a new virtue ethic for emergency medicine. 7 Med Ethics 2005; 31:567-70, doi:10.1136/jme.2004.009332.

48. Emanuel EJ, Fuchs VR. The perfect storm of overutilization. FAMA 2008;299:2789-93, doi:10.1001/jama.299.23. 2789.

49. Cassel CK, Guest J. Choosing wisely: helping physicians and patients make smart decisions about their care. $N$ Engl 7 Med 2012;307:1801-3.

50. Berwick DM, Hackbarth AD. Eliminating waste in US health care. FAMA 2012;307:1513-6, doi:10.1001/jama. 2012.362 .

51. Weinstein MC, Skinner JA. Comparative effectiveness and health care spending-implications for reform. N Engl 7 Med 2010;362:460-5, doi:10.1056/NEJMsb0911104.
52. Fisher ES, Wennberg DE, Stukel TA, et al. The implications of regional variations in Medicare spending, 2: Health outcomes and satisfaction with care. Ann Intern Med 2003; 138:288-98, doi:10.7326/0003-4819-138-4-200302180-00007.

53. Welch WG, Schwartz L, Woloshin S. Overdiagnosed: making people sick in the pursuit of health. Boston: Beacon Press; 2011.

54. Grady D, Redberg RF. Less is more: how less health care can result in better health. Arch Intern Med 2010;170:749-50, doi:10.1001/archinternmed.2010.90.

55. Berney L, Kelly M, Doyal L, et al. Ethical principles and the rationing of health care: a qualitative study in general practice. Br 7 Gen Pract 2005;55:620-5.

56. Kelen G, Kraus CK, McCarthy ML, et al. Inpatient disposition classification for the creation of hospital surge capacity: a multi-phase study. Lancet 2006;368:1984-90, doi:10.1016/S0140-6736(06)69808-5.

57. Kelen G, McCarthy ML, Kraus CK, et al. Creation of surge capacity by early discharge of hospitalized patients at low risk for untoward events. Disaster Med Public Health Prep 2009;3 Suppl 1:S1-7.

58. Darby M. Health care quality: from data to accountability. Acad Med 1998;73:843-53, doi:10.1097/00001888-19980 8000-00009.

59. Harber B, Ball E. Redefining accountability in health care. Managing Change 2003;(Spring):13-22. 


\section{APPENDIX}

\section{Opportunity costs}

A 44-year-old patient with low-risk chest pain (now asymptomatic) is told that his initial tests are normal, but he will be monitored for 6 more hours until a repeat troponin assay returns. There are three emergency medical systems (EMS) crews and multiple acutely ill patients in the waiting room, unable to access emergency care.

An elderly man occupies an acute care hospital bed for 3 months after refusing transfer to LTC. His 90-day inpatient stay blocks the equivalent of 2,160 ED stretcher hours-enough to provide emergency care for over 500 access-blocked patients.

After 3 days on the stroke unit, a 75-year-old woman with an isolated facial droop asks when she can go home. Her nurse explains that she needs teaching and therapy; she will be discharged the following Tuesday. During this time, there are many acutely ill patients blocked in the ED, unable to access inpatient care.

\section{Provider preferences, sacred cows, rules, and standard operating procedures}

A patient with osteomyelitis is kept in hospital for 6 weeks rather than receiving outpatient intravenous therapy. His doctor worries that, if discharged, he might return to injection drug use. A physician provides 1-hour counseling sessions for all patients, seeing 30 patients per week. A colleague runs group sessions for similar patients, seeing 150 per week. Outcomes appear to be similar. An ED physician orders CT imaging for $30 \%$ of midacuity patients, whereas his colleague does so in $5 \%$ of cases-with no apparent difference in patient outcomes.

Stable patients occupy monitored ED stretchers for long periods. When these are full, seriously ill patients are triaged to waiting rooms because it is "unsafe" to assess them in unmonitored care areas. After a rear-end collision, a patient spends 8 hours on an EMS gurney with a spine board and neck collar because all trauma stretchers are occupied and it is "unsafe" to assess patients in suboptimal locations. Once in the ED, a physician examines and discharges him in 5 minutes without radiographs.

Patients undergo redundant serial assessments by multiple ED nurses and physicians. Protracted sequential consultation processes-student, resident, and then attending physician-are preserved despite associated care delays (they are preferred by trainees and consulting services). Medical teaching rounds occur in the morning, pushing discharge decisions later in the day. Patient transfers and discharges are delayed until after shift change. Inpatient and ED nurses delay reporting discharges and do not "pull" patients into available beds. LTC facilities do not intake patients on weekends or holidays. Hospital discharges plummet on the weekend, whereas inflow continues.

A physician sits idle in the minor treatment area, while acute care areas are overwhelmed. Two nurses sit idle in a resuscitation room, while acute care areas are overwhelmed. Staffing levels are not matched by day and time to periods of high patient inflow.

An inpatient waits 3 days for an off-service consultation to be done before being discharged. A patient is kept in hospital 5 days awaiting an MRI because outpatient imaging delays are long. A patient has no care plan or projected discharge date; his nurse does not know when he is likely to be discharged or what discharge is dependent upon. A discharge order is written at $2 \mathrm{pm}$, when it is too late to arrange home services, so the patient stays an extra day in hospital. A discharge is intentionally delayed for 2 days to prevent an off-service admission to the bed. A discharged patient waits 8 hours in his hospital bed until a family member can drive him home. Occupational therapists block the discharge of a stable elderly patient (for weeks) because she uses a walker and will have difficulty negotiating the three steps into her house. An inpatient goes on a 3-day pass, leaving an empty bed in a hospital facing profound access block. 